\title{
Construções em Geometria Euclidiana Plana: as perspectivas abertas por estratégias didáticas com tecnologias
}

\author{
Constructions in Plane Euclidean Geometry: the Perspectives Opened by \\ Didactic Strategies with Technologies
}

Gerson Pastre de Oliveira ${ }^{*}$

Mariana Dias Gonçalves**

\begin{abstract}
Resumo
O estudo apresentado neste artigo está ligado a uma investigação qualitativa, levada a efeito junto a um grupo de estudantes do Ensino Fundamental, cuja principal finalidade consistia em estudar os processos de construção do conhecimento em geometria euclidiana plana e do teorema de Pitágoras, em particular, tendo por base a proposição de atividades problematizadas em uma estratégia didática que previa o trabalho com construções geométricas e o emprego de uma versão do software Logo, de modo a observar como este processo se estabelece de forma significativa, e a maneira pela qual a fluência em tecnologias digitais influencia na construção de conjecturas pelos sujeitos. Os pressupostos advindos da Teoria das Situações Didáticas foram adotados para a análise, em conjunto com a Teoria da Aprendizagem Significativa, e influenciaram também a construção de sequências didáticas, compostas por problemas, cujas propostas de resolução foram apresentadas pelos estudantes. Neste sentido, foi possível observar, à guisa de resultados da investigação, durante as trajetórias de resolução eleitas pelos sujeitos, diversas características da aprendizagem, entre acertos e equívocos, evidenciadas pelo uso do software e por propostas escritas nos protocolos produzidos, que permitiram, a partir desta convergência, indicar os principais avanços observados com o uso da estratégia adotada.
\end{abstract}

Palavras-chave: Teoria das Situações Didáticas. Aprendizagem Significativa. Tecnologias na Educação. Geometria Euclidiana Plana. Teorema de Pitágoras.

\begin{abstract}
The study presented in this article is linked to a qualitative research carried out with a group of primary school students, whose main purpose was to study the processes of knowledge construction in Euclidean plane geometry, considering, as main subject, the Pythagorean theorem. The research is based on the proposition of problematized activities in a didactic strategy that predicted the work with geometric constructions and the use of a version of the Logo software, in order to observe how and in what form this process is established in a significant way, and the way in which the fluency in digital technologies influences the construction of conjectures by the subjects. The assumptions derived from the Theory of Didactic Situations were adopted for the analysis, together with the Theory of Significant Learning, and influenced the construction of didactic sequences, composed of problems, which proposals of resolution were presented by the students. In this sense, it was possible to observe, as results obtained by investigation process, during the resolution trajectories chosen by the subjects, several characteristics of the subjects' learning, including correct and wrong answers, evidenced by
\end{abstract}

\footnotetext{
" Doutor em Educação (USP). Professor do Programa de Estudos Pós-Graduados em Educação Matemática (PUC/SP), São Paulo, SP, Brasil. Endereço para correspondência: Rua Marquês de Paranaguá, 111, Consolação, Prédio 1, $2^{\circ}$ andar, São Paulo, SP, Brasil, CEP: 01303-050. E-mail: gpastre@ pucsp.br.

** Mestre em Educação Matemática (PUC/SP). Professora do Colégio Bandeirantes, São Paulo, SP, Brasil. Endereço para correspondência: Rua Estela, 268, Vila Mariana, São Paulo, SP, Brasil, CEP: 04011-000. E-mail: marianadgsalgado@gmail.com.
} 
both the use of the software and written proposals in the protocols produced, which allowed, from this convergence, to indicate the main advances observed with the use of the strategy adopted.

Keywords: Theory of Didactic Situations. Significant Learning Theory. Technologies in Education. Euclidean Plane Geometry. Pythagorean Theorem.

\title{
1 Introdução
}

Não é raro que inquietações surgidas na vivência objetiva de professores e pesquisadores da área de Educação Matemática deem origem à busca de respostas, em relação a variados temas típicos, por meio da investigação científica. Em uma área com tantas articulações, o caráter das perquirições e suas gêneses podem ser encontradas a partir da observação de contextos como a sala de aula, na qual, de alguma forma, vão se consolidando práticas e reproduções de práticas que devem admitir confrontos, no sentido de constituir propostas que permitam avançar e, muitas vezes, romper com lógicas mecanicistas instauradas na forma de roteiros e de cópias sistemáticas. Segundo Fiorentini e Lorenzato (2006), esta parece ser a área adequada para propor estes questionamentos:

\begin{abstract}
[...] a Educação Matemática é uma área de conhecimento das ciências sociais ou humanas, que estuda o ensino e a aprendizagem da matemática. De modo geral, poderíamos dizer que a EM caracteriza-se como uma práxis que envolve o domínio do conteúdo específico (a matemática) e o domínio das ideias e processos pedagógicos relativos à transmissão/assimilação e/ou à apropriação/construção do saber matemático escolar. [...] Assim, podemos conceber a EM como resultante de múltiplas relações que se estabelecem entre o específico e o pedagógico num contexto constituído de dimensões histórico-epistemológicas, psicocognitivas, histórico-culturais e sociopolíticas (FIORENTINI; LORENZATO, 2006, p.5).
\end{abstract}

A expectativa deste artigo, que apresenta resultados de uma pesquisa em Educação Matemática, relaciona-se, justamente, à possibilidade de contribuir com a área no sentido de compor uma análise sobre o processo de aprendizagem de geometria euclidiana plana, ligado ao uso de construções geométricas e à aprendizagem de temas como o teorema de Pitágoras. Neste sentido, e em consonância com as afirmações que abrem este texto, pode-se dizer que as experiências em pesquisa e docência dos autores deste trabalho e, em especial, com tópicos relativos às construções geométricas, provocaram algumas inquietações, as quais, por sua vez, motivaram a realização deste estudo. Tais inquietações foram transformadas, inicialmente, em perguntas preliminares: Como fazer com que os alunos sejam protagonistas na utilização dos saberes nas construções geométricas? Como tornar significativa a aprendizagem dos conceitos geométricos? Como fazer com que os alunos deduzam as etapas envolvidas nas construções geométricas sem a intervenção direta do professor? De que forma uma estratégia didática para 
o ensino de construções geométricas, intermediada por interfaces tecnológicas digitais, pode concorrer para ampliar a autonomia de alunos no estudo de entes geométricos?

$\mathrm{Na}$ tentativa de dar conta de semelhantes inquietações, pretendeu-se verificar se a utilização de tecnologias, atrelada às sequências didáticas elaboradas com base na Teoria das Situações Didáticas (Brousseau, 2002), são proveitosas no sentido de tornar significativa a aprendizagem de tópicos de geometria plana, segundo a definição de Ausubel (2002), e promover o aluno como protagonista deste processo. Diante desta proposta, elegeu-se, dentre as diversas possibilidades estudadas no âmbito do grupo de pesquisas PEA-MAT ${ }^{1}$ (PUC/SP) uma variante do programa LOGO, de Seymour Papert e Wally Feurzeig. Desta forma, a versão chamada de SuperLogo foi utilizada como um dos elementos que condicionaram os procedimentos e mesmo as análises levadas a efeito no âmbito desta iniciativa. Como, evidentemente, pesquisa alguma, de forma isolada, poderia dar conta da variedade de perguntas iniciais mencionadas, resolveu-se objetivar a questão que norteou os esforços relativos ao trabalho aqui descrito da seguinte maneira: De que forma uma estratégia de ensino, baseada na criação de situações didáticas com uso do software SuperLogo, pode concorrer para a construção de aprendizagens significativas relacionadas às construções geométricas?

Assim, dentre as formas possíveis relacionadas ao estabelecimento de trajetórias de investigação autônomas acerca de objetos matemáticos, com o intuito de promover a aprendizagem sobre os mesmos, constam as propostas que incluem estratégias didáticas com uso de tecnologias digitais. Neste sentido, é preciso perceber que os processos de ensino de Matemática sempre ocorreram, de alguma forma, em integração com alguma tecnologia da inteligência, no sentido propugnado por Lévy (1993), uma vez que oralidade, escrita e, posteriormente, informática, assim como o conjunto de dispositivos físicos/teóricos ligados a estes recursos, estão presentes nos processos de ensino com intensidades diversas, mas sempre de maneira indissociável.

Esta presença constante, entretanto, não significa, necessariamente, um selo de qualidade: representa, antes, um desafio, solicitando que estratégias consistentes e críticas constituam a escolha dos elementos tecnológicos adequados a cada elemento do ensino. $\mathrm{Na}$ pesquisa que se descreve neste artigo, adota-se, em relação ao uso de tecnologias nas

\footnotetext{
${ }^{1}$ Grupo de pesquisas "Processo de Ensino e Aprendizagem de Matemática", vinculado ao Programa de Estudos Pós-Graduados em Educação Matemática da Pontifícia Universidade Católica de São Paulo. Dentre as principais temáticas estudadas pelo grupo, constam aquelas vinculadas à didática da Matemática, bem como as conexões entre o processo educacional e as tecnologias.
} 
atividades propostas aos sujeitos, a perspectiva teórica de Oliveira (2013). Neste constructo, o autor, inspirado em trabalhos como os de Lévy (1993), Borba e Villarreal (2005) e Tikhomirov (1981), propõe uma reflexão a respeito das fases que envolvem o uso crítico de interfaces tecnológicas em sala de aula.

Segundo Oliveira (2013), a primeira condição para que os seres humanos utilizem a tecnologia é dominar as ferramentas inerentes à interface, a partir da exploração de seus elementos e da apropriação de uma lógica subjacente. Posteriormente, a partir do momento em que a tecnologia passa a fazer parte do cotidiano dos seres humanos e de seu patrimônio de saberes, habilidades e competências, estes passam a pensar com ela, ou seja, construir conhecimentos em conjunto com as mídias sobre as quais se desenvolveu certo nível de fluência. $\mathrm{Na}$ tentativa de formular respostas a questões diversas, o indivíduo utilizará a tecnologia como elemento reorganizador de seu pensamento. Do ponto de vista educacional, os alunos passam a utilizar tal aparato para formular respostas às situações-problema, conjecturando e experimentando suas hipóteses.

Em seguida, a tecnologia surge como possibilidade de ampliar a exploração dos conceitos antes consolidados. Nessa etapa, os estudantes percebem que é possível visualizar as conjecturas propostas e refletir sobre elas, de modo a criar conclusões válidas a respeito do objeto matemático.

Por fim, na última fase do constructo teórico proposto pelo autor, o indivíduo pode ser instado a elaborar estratégias com a tecnologia, de modo a aplicar os conhecimentos adquiridos a outros contextos e outras situações, o que significa estimular o percurso investigativo autônomo. Nesse momento, os estudantes são capazes de aplicar tais conceitos a outras áreas e outros problemas propostos, expandindo seu conhecimento. Como observação adicional, o autor ressalta que o ciclo é apenas uma das muitas formas de representação possível para a trajetória mencionada, que não é nem linear, nem hierárquica, nem única (Figura 1). 


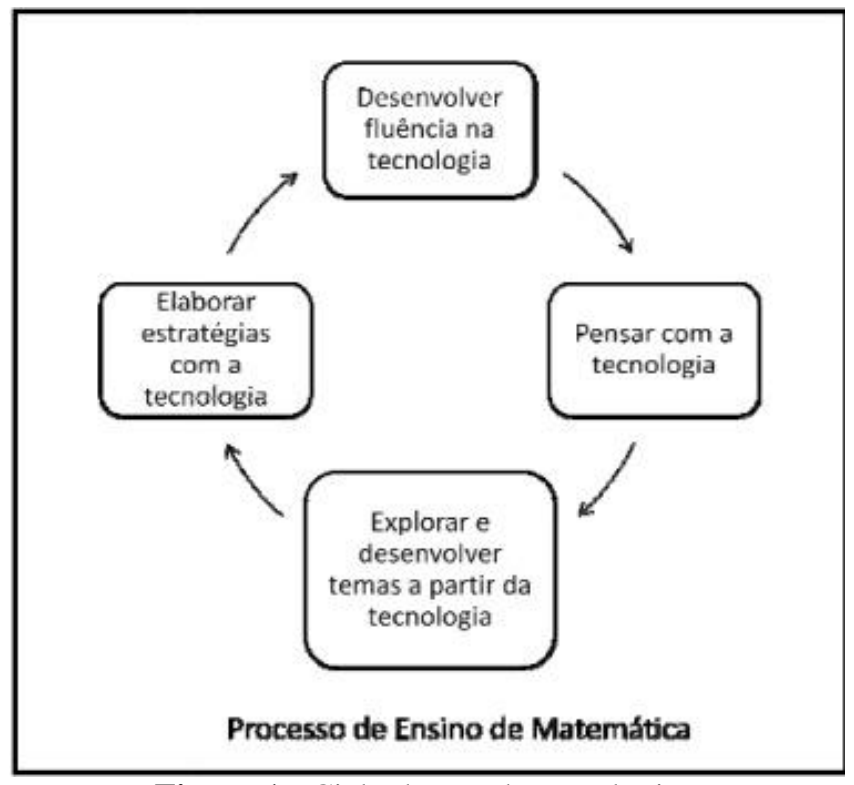

Figura 1 - Ciclo do uso de tecnologias Fonte: OLIVEIRA (2013, p. 12).

Nesse contexto, com bases em experimentos didáticos mais adiante descritos, procurou-se estruturar os encontros da pesquisa de campo de modo a promover os ciclos apontados por Oliveira (2013). Especificamente, em relação à dinâmica das atividades, no primeiro encontro, os alunos foram apresentados à tecnologia, o que possibilitou explorar os elementos da interface e conhecer a lógica da mesma, por meio de atividades de aproximação, que visaram, justamente, explorar a lógica de funcionamento da mesma. Na segunda e terceira sessões, os sujeitos foram convidados a construir figuras planas e polígonos regulares, revisitando conceitos como ângulo externo, soma dos ângulos internos e externos de um polígono regular, conjuntos numéricos e números irracionais, para enfim trabalharem o conceito do Teorema de Pitágoras, mesmo sem terem sido apresentados formalmente a ele. Finalmente, no último encontro, os alunos puderam elaborar estratégias utilizando esse conceito matemático para a resolução de problemas não familiares e desafiadores. Em todos os encontros da pesquisa de campo, os indivíduos foram instigados a perpassar o ciclo do uso de tecnologias por meio de atividades cuidadosamente concebidas para tal, de acordo com o exposto na Figura 1.

Neste artigo, especificamente, as atividades do último encontro são descritas e analisadas. Tais atividades são, desta forma, constituintes de uma pesquisa ${ }^{2}$ envolvendo aspectos ligados à Educação Matemática com uso de tecnologias digitais. No caso deste estudo, foram levantados e analisados dados sobre um grupo de cinco estudantes do $8^{\circ}$ ano do

\footnotetext{
${ }^{2}$ Esta pesquisa integra o rol de investigações realizadas pelo grupo PEA-MAT e que foram financiadas pelo CNPq (Processo no. 477783/2013-9), pela FAPESP (Processo no. 13/23228-7) e pela CAPES (bolsa mestrado).
} 
Ensino Fundamental e a sua trajetória na compreensão de construções relativas à geometria euclidiana plana. As seções que seguem levantam as teorias envolvidas na construção da pesquisa, a metodologia empregada, os resultados obtidos em um conjunto de atividades e as análises realizadas.

\section{A Teoria das Situações Didáticas}

Em contraposição à didática por assim dizer "clássica" da Matemática, na qual o conhecimento é transmitido e imposto pelo professor, as reflexões de Guy Brousseau, educador e pesquisador francês, na Teoria das Situações Didáticas (TSD), propõem a construção do conhecimento por meio de um processo que simula a atividade científica do matemático ao resolver problemas; ao mesmo tempo, indicam a importância das interações entre as pessoas envolvidas e dos movimentos dialéticos que implicam em reflexões acerca de atividades planejadas para que os envolvidos pensem e argumentem em torno das conjecturas que julguem adequadas à resposta de certos desafios propostos.

Segundo Brousseau (2002), o ensino e a aprendizagem da Matemática estão relacionados a três componentes indissociáveis: o professor, o aluno e o saber. Esses componentes formam o que o pesquisador intitula de triângulo didático. A tríade denota a relação que cada elemento tem com os demais e sua rede de influências, conforme pode ser visto na Figura 2.

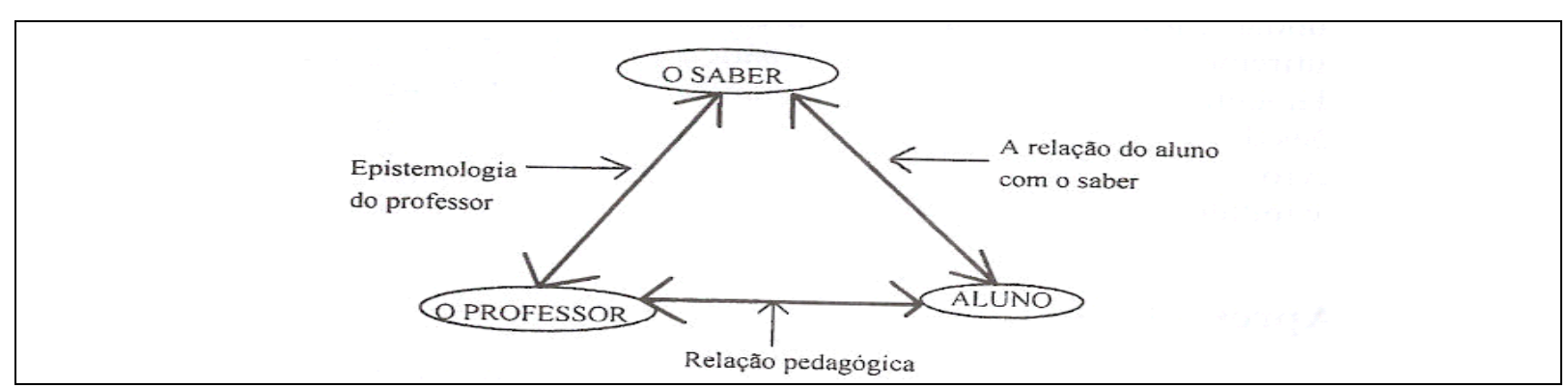

Figura 2 - O triângulo didático

Fonte: ALMOULOUD (2007, p. 35).

O professor e o saber relacionam-se na função do docente em recontextualizar o saber científico matemático para que seja compreensível e inteligível aos estudantes, enquanto os alunos relacionam-se com o saber em seu trabalho cognitivo, por meio de investigações, reorganizando o saber matemático para aplicá-lo a situações-problema. Por fim, o estudante e o professor têm uma relação pedagógica, simulando uma pequena sociedade científica, na 
qual os alunos possam ser mobilizados a aplicar os conhecimentos prévios na descoberta de um novo conhecimento.

Ainda de acordo com Brousseau (2008, p. 34), “o aluno aprende adaptando-se a um milieu que é fator de contradições, dificuldades e desequilíbrios". Esse milieu é um sistema antagonista responsável por incitar o desequilíbrio propulsor de uma nova aprendizagem, já que é capaz de engajar os estudantes na busca pelo conhecimento matemático. Assim, eventuais progressos no trabalho de construção do conhecimento se dão a partir das retroações em relação ao milieu, constituído por problemas, meio social, instrumentos, ferramentas, tecnologias e os aspectos epistemológicos, históricos e cognitivos eventualmente presentes no trato com o objeto matemático em jogo. É, justamente, no âmbito do milieu que se pode compreender o papel das mídias componentes das estratégias didáticas empregadas em determinado sistema de ensino em um dado momento: adotadas a partir do planejamento do professor, constituem uma possibilidade para a promoção da reorganização do pensamento dos estudantes, com vistas à constituição de um saber - ou seja, neste trabalho, as tecnologias, constituintes do milieu, são vistas como constam nas descrições de Oliveira (2009), a partir da reconfiguração que apresenta do triângulo didático original, como indicado na Figura 3.

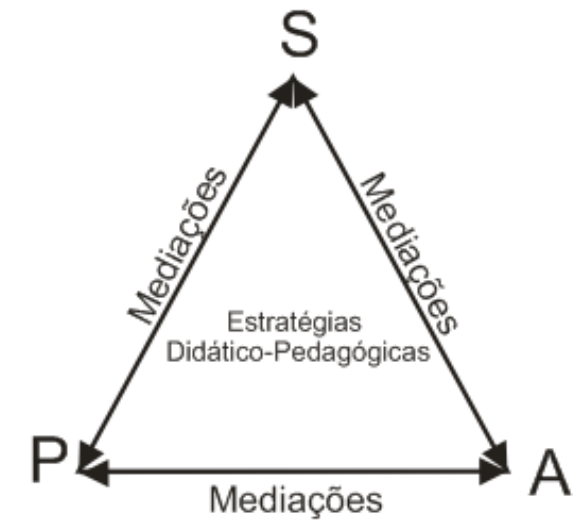

Figura 3 - Reconfiguração do triângulo didático Fonte: OLIVEIRA (2009, p. 229).

\begin{abstract}
As setas representam os fluxos, nos sentidos pretendidos por LÉVY (1993), que proporcionam, através das mediações negociadas entre as figuras humanas do processo (professores e alunos), a construção do conhecimento matemático de múltiplas maneiras (individualmente, cooperativamente, colaborativamente), previstas pelas estratégias didático-pedagógicas, as quais também, admitem reconfigurações de acordo com a dinâmica que se efetiva no saber ensinado. As mediações são as ambiências das TICs e das mais diversas tecnologias envolvidas nos processos de ensinar e aprender Matemática (OLIVEIRA, 2009, p. 229-230, grifo nosso).
\end{abstract}

Ainda no âmbito da teoria proposta por Brousseau (2008) e considerando o papel das tecnologias na forma supramencionada, o professor tem a função de apresentar aos alunos um 
bom problema, capaz de mobilizar elementos da estrutura cognitiva dos estudantes, os quais, todavia, não são suficientes para responder às questões suscitadas. A trajetória de resolução, então, permanece pautada por dialéticas de ação, formulação e validação, vistas como adidáticas, no sentido de que, em seu curso, o aprendiz não deve perceber a intencionalidade didática do proponente. Por um movimento didático, a cargo do professor, que recebe o nome de institucionalização, marcado por discussões coletivas acerca daquilo que foi discutido anteriormente, e no qual o estatuto formal do conhecimento matemático é fixado pelo docente, o novo conhecimento, surgido como resposta à problemática levantada, passa a constituir o patrimônio cognitivo do grupo envolvido.

Em termos processuais, o docente deve apresentar determinado problema aos alunos, que deverão construir estratégias para resolver a situação proposta, fase denominada de dialética de ação. Em seguida, os alunos são convidados a elaborar conjecturas em torno desse problema e comunicá-las aos seus colegas, o que permitirá o desenvolvimento da dialética da formulação. Face à discussão proposta, os alunos devem organizar suas proposições em torno de demonstrações mais robustas sobre o tema e convencer seus colegas de que elas são válidas dentro de um sistema de regras pré-determinadas, marcando a dialética da validação. Deve-se entender, apesar da exposição estruturada aqui feita, que as fases mencionadas não se apresentam de forma linear e/ou hierárquica, mas se interpenetram e sobrepõem, de maneira a permitir múltiplas e distintas trajetórias, marcadas por idas e vindas ao longo das dialéticas. Por fim, cabe ao professor o reconhecimento externo, conferindo a validade cultural do que foi proposto, além de organizar e sintetizar o novo conhecimento, o que compõe a dialética da institucionalização.

As dialéticas propostas pelo autor francês, quando estrategicamente organizadas em torno de bons problemas, não somente permitem evidenciar a estruturação cognitiva do conhecimento, assim como são capazes de aguçar o espírito investigativo dos estudantes, promovendo uma argumentação que tem elementos matemáticos como base e a elaboração de conjecturas, atividades essenciais ao trabalho de um matemático, que é o que se quer simular.

$\mathrm{Na}$ investigação apresentada neste artigo, esta teoria serviu de base para a construção de problemas adequados ao trabalho investigativo dos sujeitos, bem como permitiu analisar os avanços cognitivos dos mesmos ao longo das dialéticas. Entretanto, para compreender o papel dos conhecimentos prévios neste processo, além da TSD, a pesquisa aqui relatada utiliza outro constructo teórico, como se descreve a seguir. 


\section{Elementos da teoria de aprendizagem significativa}

O conceito de aprendizagem significativa foi proposto pelo psicólogo e pedagogo norte-americano David Ausubel. Em sua obra, Ausubel (2002) destaca que um dos objetivos da escola em uma sociedade democrática é desenvolver os estudantes, de modo que eles possam pensar de maneira sistemática, independente e crítica, empregando os conhecimentos adquiridos na resolução de problemas práticos.

Segundo o autor, existem dois tipos de aprendizagens distintas: a mecânica (rote learning) e a significativa (meaningful learning). Ao contrário da aprendizagem mecânica, na aprendizagem significativa o conhecimento relaciona-se de maneira substantiva e não arbitrária com elementos já existentes na estrutura cognitiva do indivíduo, o que favorece a aquisição e a retenção do conhecimento. Mais do que a mera memorização de conceitos, a aprendizagem significativa implica em um processo que supõe a interação de ideias âncoras pré-existentes na estrutura cognitiva do sujeito e os conceitos novos. O que Pierre Bourdieu critica em seus ensaios sobre a educação é, certamente, o ensino como produto de uma aprendizagem mecânica, não contestatória, que ratifica e reproduz as desigualdades sociais.

Além disso, a aprendizagem mecânica tem algumas consequências negativas frente à aquisição e à retenção do conhecimento. De acordo com Ausubel (2002), a mente humana, diferentemente de um computador, não consegue trabalhar com eficácia a informação relacionada de maneira arbitrária e literal em sua estrutura cognitiva; por isso, só é capaz, geralmente, de reter informações pequenas por curtos períodos de tempo. Os conceitos aprendidos de forma mecânica são vulneráveis à interferência de outros similares, já que não há vínculo estabelecido entre as ideias âncoras e os novos conceitos. Além disso, o processo envolvido no estabelecimento de uma aprendizagem significativa é capaz de despertar a curiosidade intelectual dos estudantes, envolvendo-os na construção do próprio conhecimento.

Para que ocorra uma aprendizagem significativa, o autor aponta para alguns pressupostos, como a utilização de um material potencialmente significativo, a existência de ideias âncoras devidamente organizadas e a predisposição dos indivíduos em efetivamente aprender. Dessa forma, cabe ao professor elaborar criteriosamente as atividades que sejam capazes de mobilizar os conceitos previamente presentes na estrutura cognitiva do estudante, denominados subsunçores. No caso desta pesquisa, os problemas alinhados - e, particularmente, o descrito mais adiante - levavam em consideração os conhecimentos anteriores em geometria plana como base para a consecução das atividades, cujos 
pressupostos específicos eram desconhecidos pelos sujeitos. Neste sentido, cabem algumas considerações sobre as construções geométricas.

\section{Aprendizagem da geometria plana, construções e o Teorema de Pitágoras}

A Geometria é o ramo da Matemática que se dedica ao estudo do espaço e das formas existentes - não sem razão, Freudenthal (1973) afirmava que "geometria é compreender o espaço" (p. 469). Além de surgir na base da consolidação da Matemática como campo de conhecimento por meio de postulados, teoremas e uma lógica subjacente, a Geometria permite o estabelecimento de uma relação entre o mundo real e o conceitual, o concreto e o abstrato. O contato com a Geometria permite que os estudantes, desde cedo, por exemplo, investiguem, visualizem e experimentem em relação aos objetos presentes em seu redor e desenvolvam noções de orientação espacial.

Neste sentido, uma das maneiras de estudar este domínio da Matemática ocorre por meio das chamadas construções geométricas, que podem ser vistas como maneiras de expressar graficamente a forma de determinados entes geométricos, ou seja, representações dos mesmos. Subentende-se, assim, à realização de construções desta natureza, o conhecimento das propriedades e definições matemáticas do objeto em questão. Isto implica dizer, em outras palavras, que uma construção geométrica não se reduz a um simples desenho despretensioso, mas pressupõe a mobilização dos conhecimentos prévios a respeito dos objetos matemáticos, dos domínios de validade dos entes geométricos e de suas propriedades.

No trabalho aqui discutido, a escolha do Teorema de Pitágoras como ente matemático está relacionada à sua importância na resolução de problemas e na aprendizagem de outros conceitos, além de sua aplicação a outras áreas da ciência, como a Astronomia e a Física Óptica. Apesar de já conhecido por diversos povos antigos, como egípcios e babilônios, atribui-se a Pitágoras de $\operatorname{Samos}(570$ a. C) a demonstração de sua validade a todos os triângulos retângulos, por meio de uma abstração.

Segundo evidenciado por Maor (2007), o Teorema de Pitágoras, amplamente difundido do ponto de vista da relação algébrica entre três valores, $\boldsymbol{a}^{2}=\boldsymbol{b}^{2}+\boldsymbol{c}^{2}$ (a soma das medidas dos quadrados dos catetos de um triângulo retângulo é igual ao quadrado da medida da hipotenusa desse mesmo triângulo), na verdade, não foi a visão de Pitágoras naquela época. Para o filósofo grego, o teorema tratava de uma relação entre áreas, como 
esquematizado na Figura 3. Nela, a área do quadrado maior (hachurada em cinza claro na Figura 4) é igual à soma das áreas dos quadrados menores (hachurados em cinza escuro).

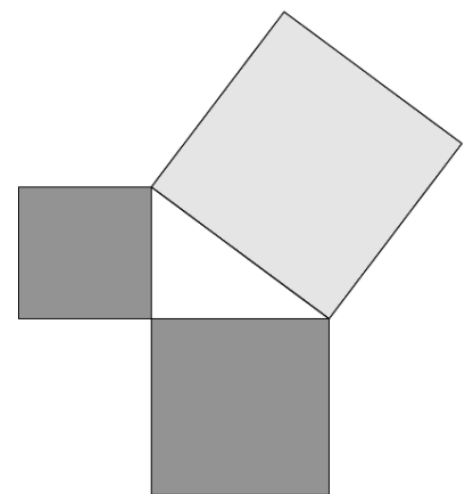

Figura 4 - O Teorema de Pitágoras como relação entre áreas.

Fonte: Elaborado pelos autores

Para que esta relação pudesse ser enunciada como teorema, fez-se necessário demonstrá-la com rigor e generalizá-la para todos os triângulos retângulos. São conhecidas mais de 371 demonstrações do Teorema de Pitágoras, normalmente divididas em dois grupos: as demonstrações algébricas, baseadas nas relações métricas de um triângulo retângulo, e as demonstrações geométricas, baseadas na equivalência de áreas. A seguir, apresenta-se uma demonstração geométrica do Teorema de Pitágoras, escolhida devido à sua relação com as atividades desenvolvidas na sequência didática empregada com os sujeitos da pesquisa aqui descrita.

Considere um triângulo retângulo cujos catetos medem, em determinada unidade, $b$ e $c$ e a hipotenusa mede, na mesma unidade, $a$. Deve-se demonstrar que $\boldsymbol{a}^{\mathbf{2}}=\boldsymbol{b}^{\mathbf{2}}+\boldsymbol{c}^{\mathbf{2}}$. Assim, constroem-se dois quadrados de lados medindo $b+c$, conforme mostra a figura 5 :

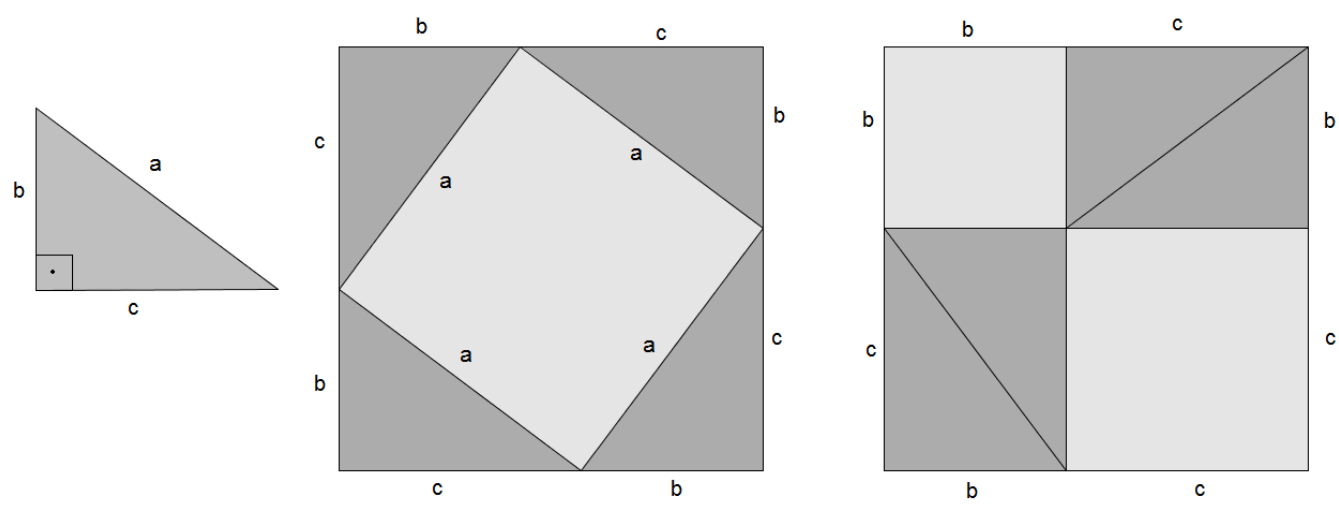

Figura 5 - Demonstração geométrica do Teorema de Pitágoras Fonte: Elaborado pelos autores

No primeiro quadrado (ao centro), constroem-se quatro triângulos congruentes ao triângulo desenhado anteriormente. Os catetos desses triângulos devem estar apoiados no lado 
do quadrado inicial, como indicado na figura. No segundo quadrado (à direita na figura supramencionada), constroem-se dois quadrados menores, um de lado $b$ e o outro de lado $c$. Além disso, traçam-se as diagonais dos retângulos de lados $b$ e $c$, obtendo quatro triângulos de lados $b$ e $c$ congruentes ao triângulo inicial.

A respeito da área do primeiro quadrado, tem-se que $(b+c)^{2}=a^{2}+4 \cdot\left(\frac{b \cdot c}{2}\right)$. Em relação à área do segundo quadrado, tem-se que $(b+c)^{2}=b^{2}+c^{2}+4 .\left(\frac{b \cdot c}{2}\right)$. Como os dois quadrados mencionados são congruentes, pode-se afirmar que suas áreas são equivalentes, e, portanto, $a^{2}+4 \cdot\left(\frac{b \cdot c}{2}\right)=b^{2}+c^{2}+4 \cdot\left(\frac{b . c}{2}\right) \Rightarrow a^{2}=b^{2}+c^{2}$. A Figura 6 representa um destaque do primeiro quadrado desenhado.

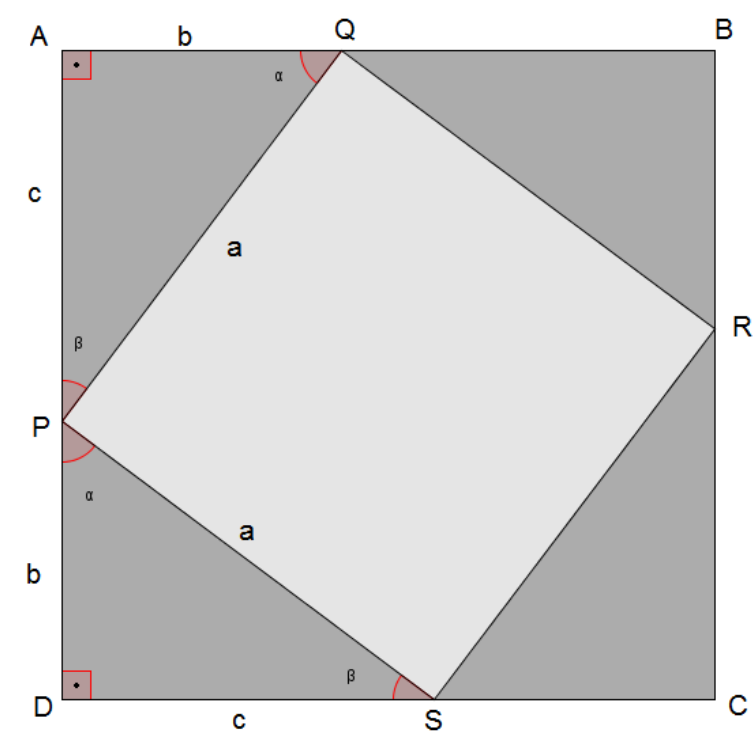

Figura 6 - Detalhe do quadrado construído ao centro Fonte: Elaborado pelos autores

Observa-se que, após a construção dos triângulos $A P Q, P D S, Q B R$ e $R C S$, obtém-se o quadrilátero $P Q R S$ ao centro. Analogamente, pode-se provar que $P Q R S$ é um quadrado porque:

- Os lados $\overline{\boldsymbol{P Q}}, \overline{\boldsymbol{Q R}}, \overline{\boldsymbol{R S}} \boldsymbol{e} \overline{\boldsymbol{S P}}$ são congruentes, uma vez que todos medem $a$. Logo, pode-se afirmar que o quadrilátero $P Q R S$ é losango.

- Como os triângulos $A P Q$ e $D P S$ são retângulos em $A$ e $D$, respectivamente, tem-se que medida $A \widehat{Q} P+$ medida $Q \widehat{P} A=90^{\circ}$ e medida $D \widehat{P} S+$ medida $D \widehat{S} P=$ $90^{\circ}$

- Como os triângulos $A P Q$ e $D P S$ são congruentes, tem-se que medida $\boldsymbol{D} \widehat{\boldsymbol{P}} \boldsymbol{S}=$ medida $A \widehat{Q} P$ e medida $Q \widehat{P} A=$ medida $D \widehat{S} P$. 
- Observando que $\boldsymbol{D} \widehat{\boldsymbol{P}} \boldsymbol{A}$ é raso, tem-se que medida $\boldsymbol{D} \widehat{\boldsymbol{P}} \boldsymbol{S}+\operatorname{medida} \boldsymbol{S} \widehat{\boldsymbol{P}} \boldsymbol{Q}+$ medida $Q \widehat{P} A=180^{\circ}$.

- Substituindo as duas primeiras relações na última relação, obtém-se:

$$
\begin{aligned}
& \text { medida } D \widehat{P} S+\text { medida } S \widehat{P} Q+\text { medida } Q \widehat{P} A=180^{\circ} \Rightarrow \\
& \text { medida } A \widehat{Q} P+\text { medida de } S \widehat{P} Q \text { medida } Q \widehat{P} A=180^{\circ} \Rightarrow \\
& 90^{\circ}+\text { medida de } S \widehat{P} Q=180^{\circ} \Rightarrow \text { medida de } S \widehat{P} Q=90^{\circ}
\end{aligned}
$$

- De forma análoga para os outros ângulos internos do quadrilátero $P Q R S$, pode-se concluir que todos são retos. Dessa maneira, pode-se afirmar que o quadrilátero em questão é um retângulo.

- Como o quadrilátero $P Q R S$ é, simultaneamente, losango e retângulo, conclui-se que ele é quadrado e que a medida de sua área é $\boldsymbol{a}^{2}$.

Hoje, mais do que uma ferramenta utilizada na Matemática, o Teorema de Pitágoras pode ser aplicado a problemas práticos envolvendo, por exemplo, o cálculo da distância alcançada pela vista de um ser humano na linha do horizonte, o cálculo da rota de aviões na aeronáutica para que não haja colisões, a determinação da medida do raio da Terra, entre outras aplicações.

No decorrer da vida acadêmica dos estudantes, o Teorema de Pitágoras revela-se importante em diversos momentos, como, por exemplo, na determinação da medida da diagonal de um quadrado, no cálculo da altura do triângulo equilátero, na determinação da $1^{\mathrm{a}}$ relação fundamental da trigonometria, qual seja $\operatorname{sen}^{2} x+\cos ^{2} x=1$, no cálculo da medida da diagonal de um paralelepípedo, em problemas práticos envolvendo trapézios retângulos, na relação entre a altura, a geratriz e o raio da base de um cone reto, no estabelecimento da relação entre as medidas dos eixos de uma elipse e a sua distância focal, entre outras possibilidades.

No que concerne às construções geométricas, o Teorema de Pitágoras embasa o trabalho com régua e compasso envolvendo triângulos retângulos, a construção de segmentos incomensuráveis (por exemplo, $\sqrt{\mathbf{2}}, \sqrt{\mathbf{3}}, \sqrt{\mathbf{5}}$ e $\sqrt{\mathbf{6}}$ ), a construção da média aritmética, média harmônica e média geométrica de dois segmentos dados, etc. No que diz respeito ao ensino e à aprendizagem do Teorema de Pitágoras, as construções geométricas revelam-se uma forma interessante de aproximar a geometria à relação algébrica envolvida. Nesse sentido, na sequência didática elaborada para a pesquisa que aqui se descreve, optou-se por utilizar as construções geométricas como forma de abordagem inicial do Teorema de Pitágoras. Além 
disso, especificamente, na investigação descrita neste artigo, as construções geométricas foram propostas a partir do acesso dos sujeitos às tecnologias específicas, descritas a seguir, juntamente com outros detalhes pertinentes à metodologia.

\section{Organização da pesquisa e descrição das atividades}

Os dados que nortearam a redação deste texto foram coletados com um grupo de cinco estudantes do $8^{\circ}$ ano do Ensino Fundamental, de uma escola do município de Guarulhos, São Paulo, na qual foram realizados quatro encontros, que ocorreram especificamente no laboratório de informática da instituição. Como forma de estabelecer o diálogo colaborativo entre os estudantes, eles foram dispostos em grupos para a realização das atividades propostas. A observação das reações dos alunos às atividades foi registrada na forma de anotações, fotografias e filmagens e o controle das situações realizadas aconteceu por meio de protocolos, nos quais os sujeitos apontaram suas conjecturas e tentativas, bem como eventuais conclusões ao final de cada etapa.

Os problemas apresentados aos estudantes, todos relativos a construções no âmbito da geometria plana, tinham como instrumentos as mais diversas mídias, o que incluía, além do computador com o software SuperLogo, artefatos mais "tradicionais", por assim dizer, como papel, lápis, régua, esquadro e transferidor. Entretanto, a questão examinada neste trabalho se refere especificamente à forma pela qual a elaboração de uma estratégia didática com o uso do programa computacional mencionado poderia concorrer para a consolidação de aprendizagens significativas relacionadas às construções geométricas. Desta forma, o uso de tecnologias justifica-se no embasamento teórico desta pesquisa, já que representa uma forma de, por meio de estratégias didáticas adequadas, incentivar o estudante à criação de novas conjecturas, à elaboração de testes relacionados à sua hipótese inicial e, finalmente, à criação e discussão de soluções parciais, sem que haja a interferência direta do professor.

O software escolhido para a intermediação das atividades, o SuperLogo, é uma tradução/adaptação da criação original, o Logo, uma linguagem desenvolvida por Seymour Papert, na década de 1960, no Massachusetts Institute of Technology (MIT). O SuperLogo é, na verdade, uma versão concebida pelo Núcleo de Informática Aplicada à Educação (NIED) da Universidade de Campinas (UNICAMP). A utilização do SuperLogo possibilita não somente o estudo da geometria, como também o emprego de uma lógica de programação que permite a elaboração de conjecturas, a verificação de hipóteses, a investigação e a recondução 
dos procedimentos em caso de erro. De forma mais específica, a linguagem traz, em sua janela de movimentação, um cursor semelhante a uma tartaruga, o qual pode ser movimentado a partir de comandos como "para frente" (PF), "para trás" (PT), "para direita" (PD) e "para a esquerda" (PE). A movimentação mencionada, e originada por estes e outros comandos, pode deixar "rastros", ou seja, segmentos, arestas, entre outros elementos, que permitem visualizar e avaliar a construção realizada.

As atividades que representam os objetos centrais das análises realizadas neste artigo constituem uma parte dentre as que foram propostas ao longo das sessões mencionadas, mais especificamente aquelas trabalhadas no último encontro. Em tais atividades, os alunos puderam efetivar percursos investigativos de maneira integrada à tecnologia eleita. Assim, ainda que não seja possível descrever todos os problemas trabalhados, é importante evidenciar que a lógica que permeou as atividades e sua organização foi baseada na proposta do ciclo de formação de pessoas para o uso de tecnologias na Educação Matemática, proposto por Oliveira (2013) e evidenciado na introdução deste trabalho.

O último encontro da pesquisa de campo, cujas atividades são descritas a seguir, tinha como objetivo usar os pressupostos do Teorema de Pitágoras em construções realizadas no software SuperLogo, de modo que os sujeitos tivessem a oportunidade de empregar a tecnologia digital mencionada - e outras, de outra natureza, se fosse o caso - para construir os conhecimentos necessários, empregando as estratégias que lhes parecessem mais adequadas.

Nesse encontro, estavam presentes cinco estudantes, que foram divididos em dois grupos, uma dupla e um trio. O quadro 1, a seguir, contém as atividades que os alunos deveriam realizar em parceria com o software.

\begin{tabular}{|c|c|c|}
\hline Figuras propostas & Raciocínio subjacente & Comandos esperados \\
\hline $\begin{array}{l}\text { 1. Construa um quadrado de } \\
\text { lado } 200 \text { (passos de } \\
\text { tartaruga) e uma de suas } \\
\text { diagonais. Questão sem o } \\
\text { registro figural. }\end{array}$ & $\begin{array}{l}\text { • } \\
\qquad 200 \\
d^{2}=200^{2}+200^{2} \Rightarrow \\
\Rightarrow d^{2}=40000+40000 \Rightarrow \\
\Rightarrow d=\sqrt{80000}\end{array}$ & $\begin{array}{l}\text { repita } 4 \text { [pf } 200 \text { pd 90] } \\
\text { pd } 45 \\
\text { pf raizq } 80000\end{array}$ \\
\hline
\end{tabular}




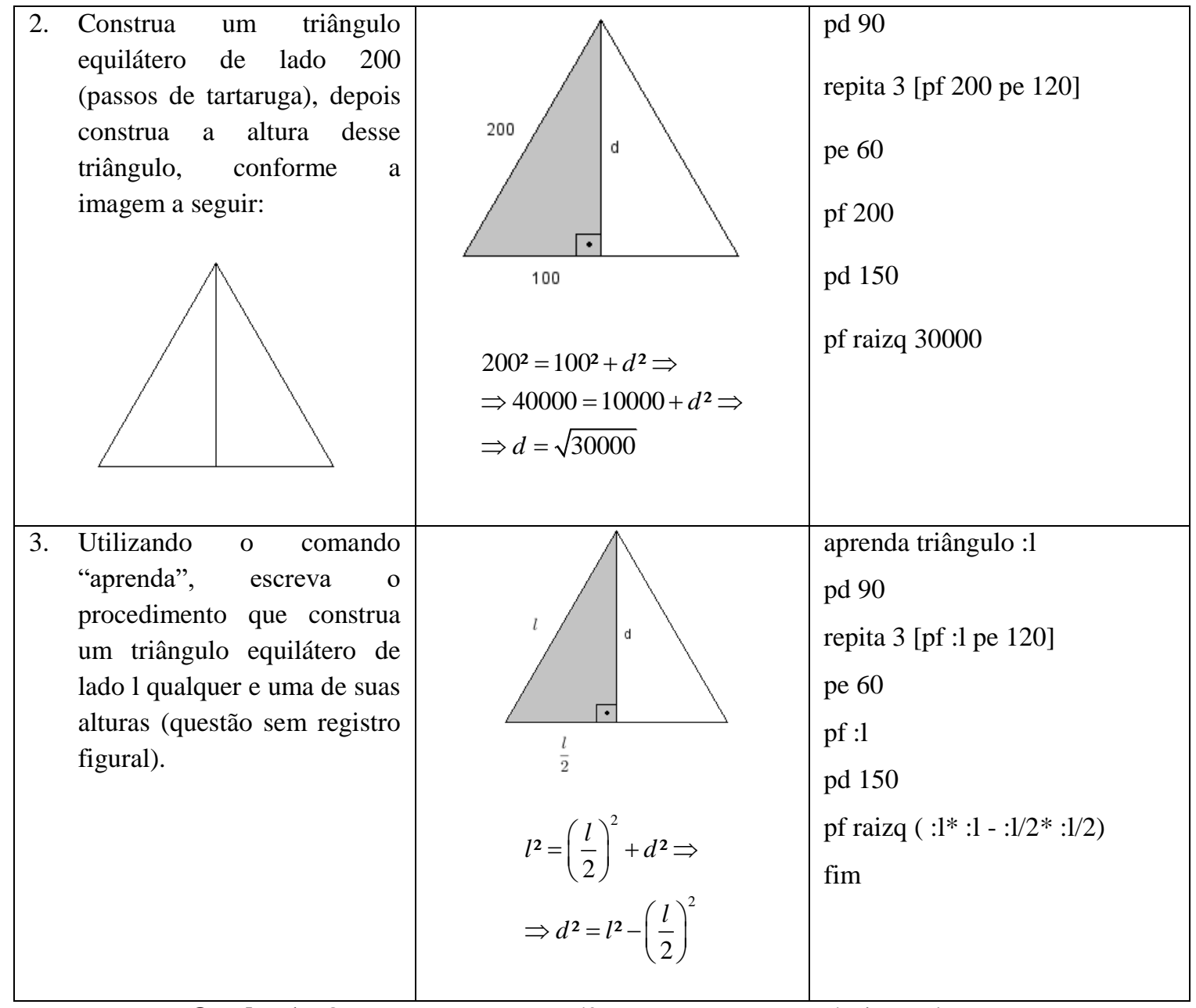

Quadro 1 - Questões propostas no $4^{\circ}$ Encontro e suas possíveis resoluções Fonte: Dados da pesquisa (2014).

Para a análise dos protocolos obtidos na pesquisa, como se descreve a seguir, optou-se por uma metodologia de caráter qualitativo, embasada nas propostas de Bogdan e Biklen (1994), já que se revelou prioritária a obtenção e análise de dados que permitissem uma abordagem descritiva, por meio da observação da perspectiva dos estudantes em relação às atividades propostas, de forma processual, como indicam os autores no tratamento de pesquisas que assumem este caráter.

Para realizarem as três atividades propostas, os sujeitos deveriam decompor os polígonos em subfiguras e aplicar o Teorema de Pitágoras aos triângulos retângulos formados. É importante salientar que os conhecimentos mobilizados nas atividades deste encontro não só envolviam o teorema de Pitágoras, “descoberto" pelos sujeitos ao longo dos encontros anteriores $^{3}$, mas também as medidas dos ângulos internos do triângulo equilátero e do

\footnotetext{
3 As tarefas anteriores, desenvolvidas nos encontros 1, 2 e 3, envolveram atividades investigativas sobre geometria plana na forma de problemas, de modo que os estudantes, que não conheciam o Teorema de Pitágoras, já que o mesmo não tinha sido apresentado formalmente a eles, descobriram-no como resposta às questões às
} 
quadrado, a medida do ângulo formado entre a diagonal do quadrado e um de seus lados, a medida do ângulo formado pela altura do triângulo equilátero e seus lados, a generalização de padrões e o cálculo envolvendo números irracionais, visto que a medida da diagonal do quadrado e da altura do triângulo equilátero descritos nas atividades são números irracionais.

A respeito da primeira questão, observou-se que ambos os grupos (a dupla e o trio) resolveram a atividade de forma correta. A ausência de registro figural nesta questão não foi um obstáculo, já que os sujeitos conheciam a forma geométrica do quadrado e a localização de suas diagonais. Observou-se que o problema envolvido nesta questão concorreu para que os alunos mobilizassem seus conhecimentos prévios, discutissem suas conjecturas e propusessem, entre si, elementos à validação do(s) outro(s). Ao final das trocas, marcadas pelos movimentos dialéticos de ação, formulação e validação, os dois grupos concluíram pela aplicação do Teorema de Pitágoras, e o fizeram de forma majoritariamente correta, como pode ser observado no protocolo constante da Figura 7.

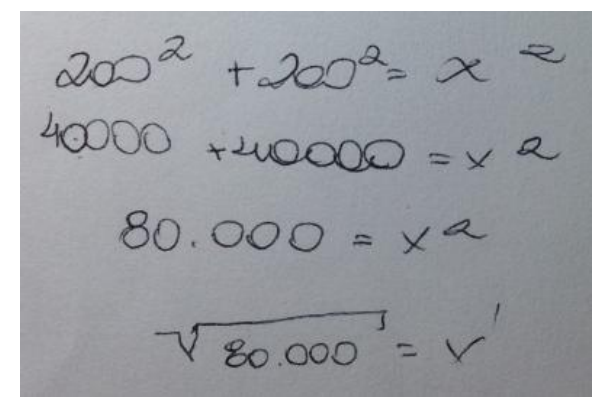

Figura 7 - Cálculo da diagonal do quadrado Fonte: Dados da pesquisa (2014).

Entretanto, nos dois grupos, foram registrados alguns equívocos e dificuldades em relação ao "ângulo de giro", por assim dizer, da tartaruga, ou seja, no que diz respeito às medidas dos ângulos envolvidos na trajetória que culminaria na construção pretendida. $\mathrm{Na}$ Figura 8, pode-se notar que a aplicação do Teorema de Pitágoras conduziu à formação da figura, ainda que com a angulação equivocada. Isto porque os sujeitos utilizaram um ângulo de $40^{\circ}$, quando deveriam ter utilizado um "giro" para direita de $45^{\circ}$, pois a diagonal do quadrado também é bissetriz de seus lados 5 .

quais foram submetidos. Trata-se de um pressuposto da TSD, que recomenda que a resposta dos problemas envolvidos nas situações didáticas seja o próprio conhecimento que se objetiva com o processo de ensino.

${ }^{4}$ A expressão "ângulo de giro" se refere à trajetória da tartaruga, ou seja, do cursor que aparece na tela e mostra a posição atual em relação ao plano. Os comandos $p d$ e $p e$, seguidos de um valor numérico, indicam um ângulo, tomado à direita ou à esquerda da posição atual, indicando, por sua vez, a nova posição a partir da qual o próximo segmento será traçado pela tartaruga, geralmente por meio dos comandos $p f$ ou $p t$.

${ }^{5}$ A proposta da TSD, levada adiante ao longo das sessões da pesquisa aqui descrita, indica que a resposta do problema utilizado para fazer com que os sujeitos conjecturem, discutam, pensem e representem suas cogitações deve ser o próprio conhecimento a ser construído. Os equívocos e eventuais imprecisões são tratados e 


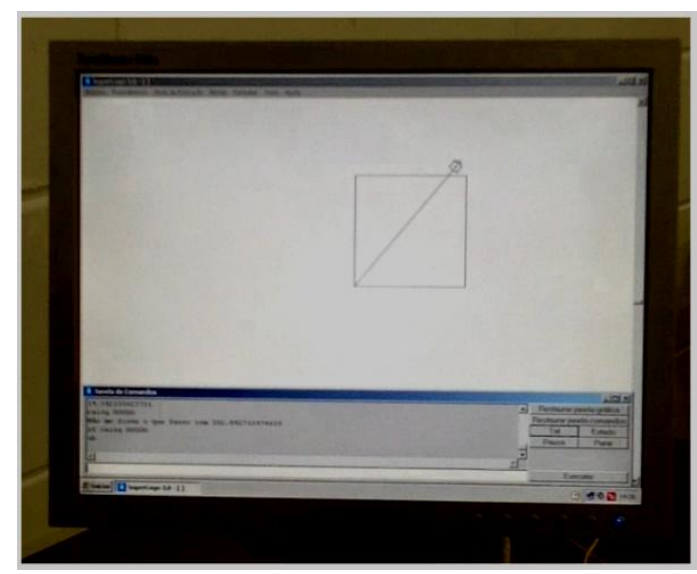

Figura 8 - Registro do erro dos sujeitos (medida do ângulo)

Fonte: Dados da pesquisa (2014).

$\mathrm{Na}$ resolução da segunda atividade, entretanto, a questão em torno da medida dos ângulos já não gerou tantas dúvidas. O protocolo da dupla, exibido em seguida, evidencia a correta aplicação do Teorema de Pitágoras e a utilização do conceito da medida do ângulo interno do triângulo equilátero na determinação do ângulo de giro da tartaruga (Figura 9).

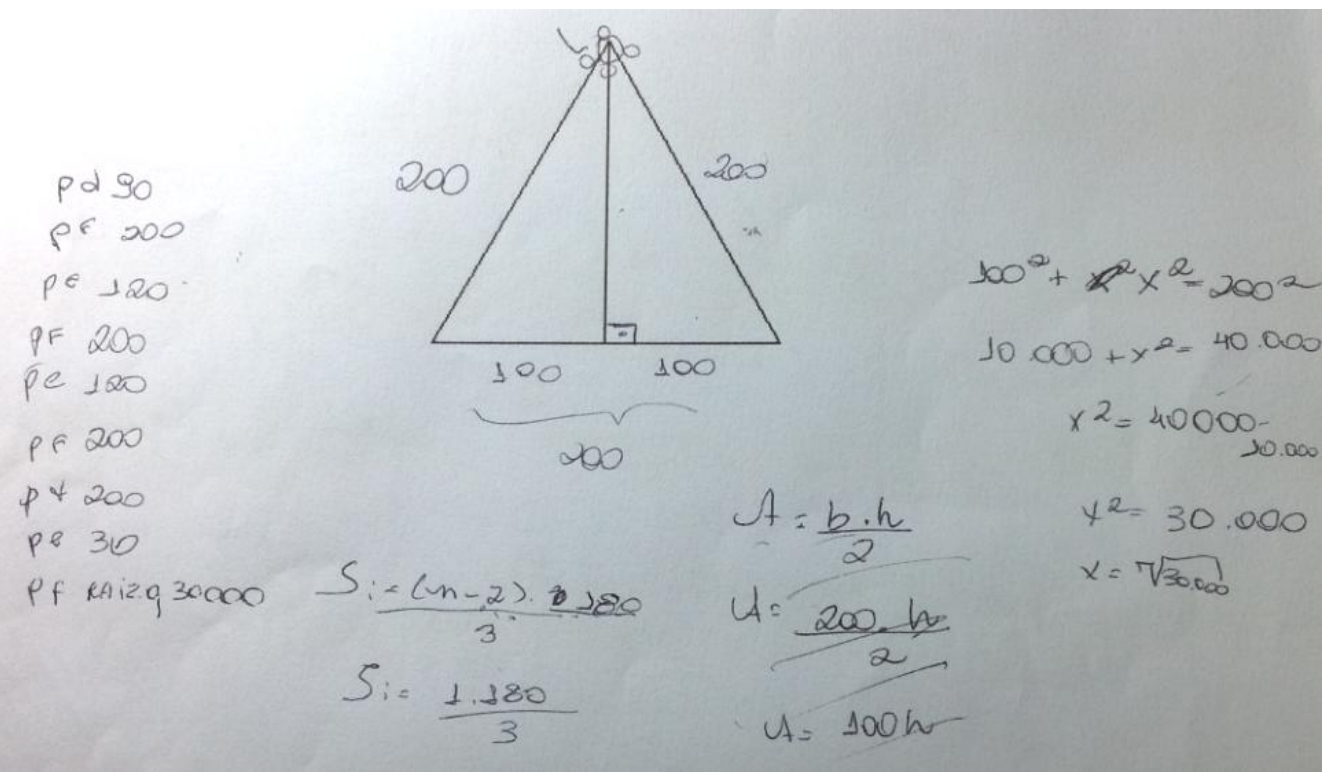

Figura 9 - Construção da altura do triângulo equilátero com o auxílio do software Fonte: Dados da pesquisa (2014).

A respeito da produção do trio, observa-se que os alunos determinaram, de forma correta, as medidas dos ângulos de giro da tartaruga. No entanto, no primeiro instante, tentaram atribuir valores para a altura do triângulo equilátero, como se nota em "pf 200, ub, pf 200, ul, pf 150, ub, pf 150, pf 180, pt 180, ul, pf 180, ub, pt 180, ul, raizq 30000, pf raizq 30000". Alternando entre os comandos $u b$ (use borracha, que faz o cursor andar sem marcar a trajetória na tela) e $u l$ (use lápis, que, por sua vez, marca a trajetória), os sujeitos estimaram

realinhados, do ponto de vista do estatuto formal do conhecimento matemático, no momento de institucionalização, o que se cuidou de fazer aqui. 
valores para a altura do triângulo equilátero. Ao final, perceberam que deveriam aplicar o Teorema de Pitágoras no triângulo retângulo para descobrir a medida de seu maior cateto (figura 10).

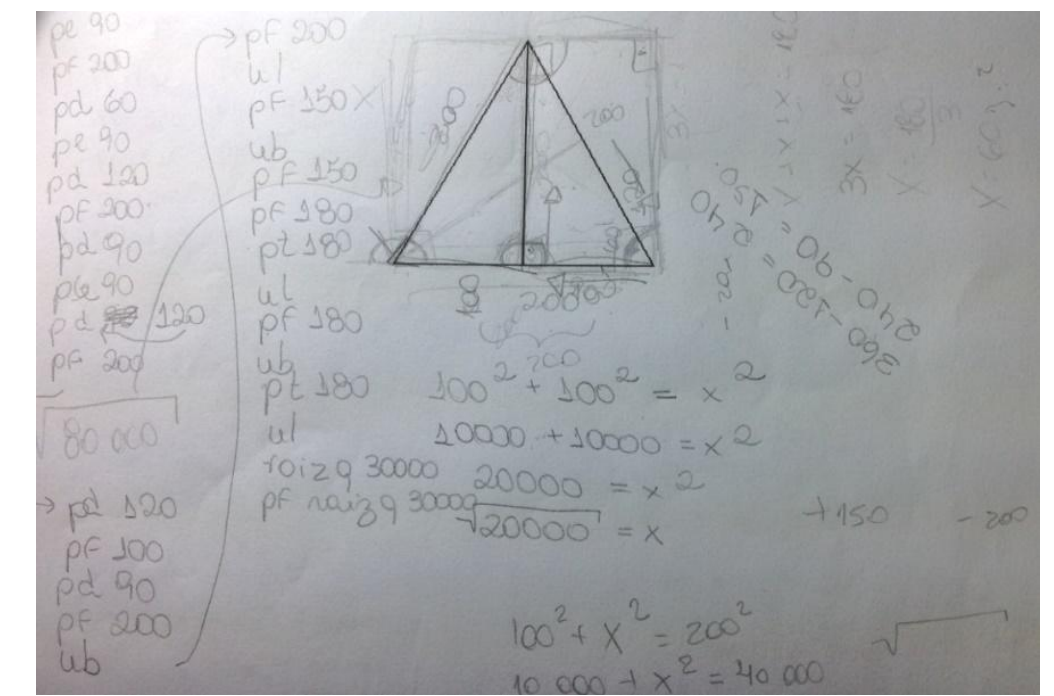

Figura 10 - Protocolo do trio na construção da altura do triângulo equilátero Fonte: Dados da pesquisa (2014).

Pode-se perceber, tanto pelas intervenções dos sujeitos ao longo das discussões, como pelos protocolos, que as experimentações que tiveram lugar durante o processo de busca pela resposta foram realizadas em conjunto com as tecnologias em uso, ou seja, as estratégias consideradas para a resolução não ocorreram dissociadas em relação ao SuperLogo e sua lógica subjacente. As percepções relativas às incorreções no raciocínio puderam ser visualizadas e remeteram os sujeitos à formulação de outras conjecturas, posteriormente validadas e certificadas como satisfatórias em relação ao objetivo perseguido.

A terceira questão consolida os elementos estudados anteriormente, além de relacionálos à utilização de uma variável $l$, que representa a medida do lado do triângulo equilátero. A atividade consistia em escrever um comando aprenda utilizando a linguagem LOGO, de modo a construir um triângulo equilátero e uma de suas alturas a partir de qualquer lado informado.

Ao ser digitado o comando aprenda no software, abre-se uma caixa de texto na qual o usuário deve escrever instruções na linguagem LOGO de modo a instruir o cursor a realizar uma série de passos lógicos em uma sequência que permita atingir o objetivo - no caso, construir o referido triângulo e sua altura. Em outras palavras, para a resolução do problema destacado aqui, o usuário do SuperLogo deve digitar uma sequência lógica que envolva uma variável, a medida do lado do triângulo, que serve de parâmetro para uma função computacional. Esta variável permitirá conferir certo grau de generalidade à função 
mencionada, no sentido de que, em tese, qualquer número real positivo serve como medida. A resposta ao problema, que consiste, de acordo com a TSD, no conhecimento a ser construído, depende do emprego do recém-descoberto teorema de Pitágoras de forma inédita para o grupo de alunos.

Do ponto de vista matemático, os sujeitos deveriam decompor o triângulo equilátero da atividade em dois triângulos retângulos, isto é, subfiguras, para então aplicarem o Teorema de Pitágoras. Cabe lembrar que os conhecimentos mobilizados nessa atividade envolviam outros conceitos, como medidas dos ângulos internos do triângulo equilátero, a medida do ângulo formado pela altura do triângulo equilátero e seus lados e cálculos envolvendo números irracionais. Ademais, para a escrita correta do comando aprenda no software, os alunos deveriam elaborar estratégias utilizando a interface envolvida, aplicando o conceito de generalização de padrões por meio de uma variável, que, neste caso, representa o lado do triângulo equilátero (descrito no Quadro 1 como:l).

Dessa maneira, os problemas propostos tinham como intenção didática incentivar a aprendizagem do Teorema de Pitágoras e a conexão com conhecimentos prévios mobilizadores, além de apontar indícios da existência de uma aprendizagem significativa.

Esta terceira atividade tinha um grau de dificuldade maior, se comparada com as atividades presentes nesta e em outras sessões da pesquisa de campo, visto que era desprovida de imagens (os sujeitos receberam apenas o enunciado, sem qualquer ilustração) e envolvia a criação de um procedimento, isto é, uma função lógica para a construção de qualquer triângulo equilátero. Além dos conhecimentos matemáticos mobilizados, a lógica de programação envolvida poderia ser um entrave à resolução do problema. Portanto, a questão selecionada faz parte da classe de situações em que os sujeitos não dispõem de toda a instrumentalização necessária. De acordo com o embasamento teórico dessa pesquisa, a existência desse tipo de problema é fundamental, uma vez que leva à reflexão e à exploração de uma série de conjecturas para a resolução completa da atividade.

Em relação às resoluções apresentadas, observa-se que a dupla de sujeitos elaborou uma estratégia correta para a realização da atividade, o que conduziu a diversos acertos na composição da figura geométrica solicitada. O procedimento apresentado na Figura 11, que evidencia a construção coletiva da dupla, indica apenas um equívoco, relacionado com a manipulação algébrica relativa ao último comando, justamente aquele destinado a traçar a altura do triângulo equilátero. É possível perceber, no entanto, a consolidação dos conhecimentos geométricos necessários, já que os sujeitos enunciam a angulação do cursor 
corretamente e denotam claramente a aplicação do Teorema de Pitágoras. Assim, a construção resultante da produção destes sujeitos pode ser vista na Figura 12.

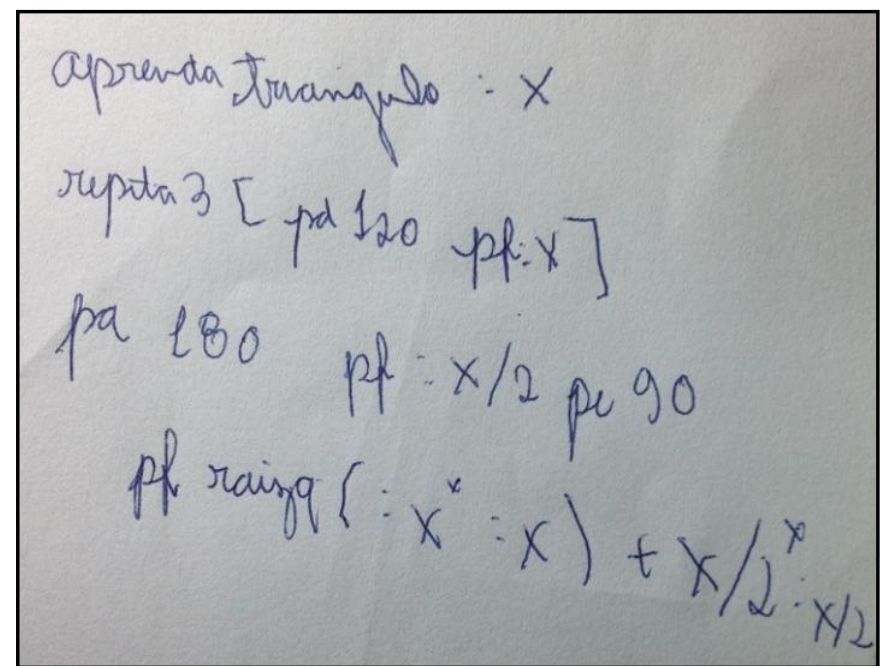

Figura 11 - Produção da dupla de sujeitos

Fonte: Dados da pesquisa (2014).

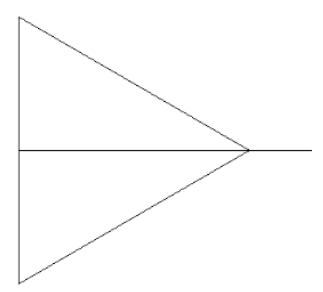

Figura 12 - Construção da dupla no SuperLogo Fonte: Dados da pesquisa (2014).

Já o trio de sujeitos realizou toda a atividade de forma correta. Os estudantes empregaram, para o problema em tela, os conhecimentos acerca do Teorema de Pitágoras, cuja construção resultou da sequência de atividades investigativas na qual se engajaram. Além disso, manipularam os elementos do software de forma adequada. Neste sentido, o grupo construiu o procedimento aprenda evidenciado na Figura 13, demonstrando o domínio dos conceitos apresentados, além da fluência necessária na linguagem LOGO.

$\mathrm{Na}$ descrição da estratégia empregada pelo grupo, é possível notar que os estudantes reavaliam as ações tomadas e traçam outros caminhos para a realização da atividade, principalmente pela dificuldade de manipulação algébrica. Essa dificuldade dos dois grupos de sujeitos pode ser justificada pela sequência de conteúdos listada no currículo da escola na qual estão matriculados. A manipulação de potências e radicais envolvendo o conjunto dos números reais seria trabalhada apenas na série subsequente àquela dos estudantes à época da pesquisa, o que torna ainda mais relevante os resultados aqui apurados, se considerado o referencial teórico empregado. 


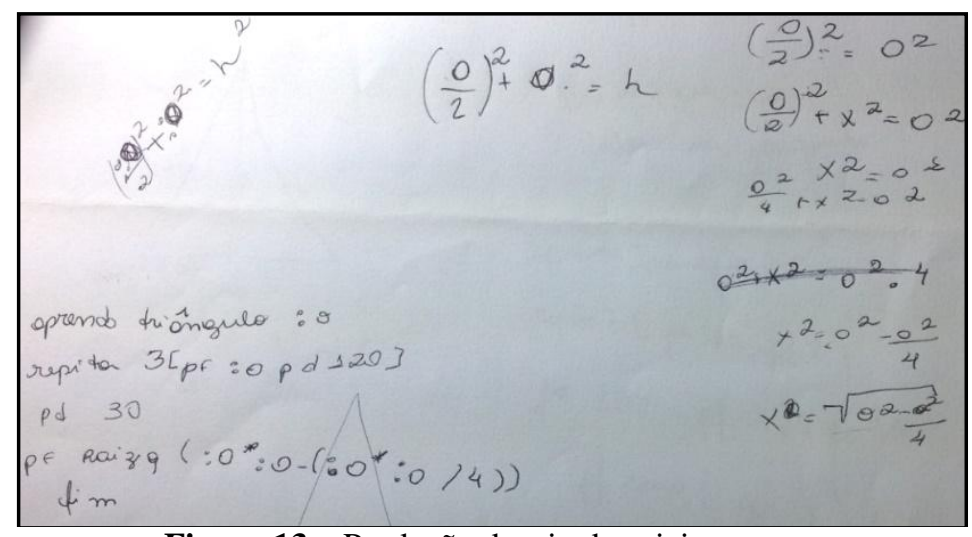

Figura 13 - Produção do trio de sujeitos Fonte: Dados da pesquisa (2014).

No que diz respeito à Teoria das Situações Didáticas, as atividades do último encontro previsto na organização da pesquisa de campo foram estruturadas de modo a perpassar as dialéticas propostas em torno de um milieu antagonista.

A partir de tentativas, em um primeiro momento, os estudantes buscam construir o triângulo equilátero e uma de suas alturas, sem que haja a procura por uma justificativa matemática formal apropriada (dialética de ação). A criação do procedimento aprenda para a construção das figuras propostas mobiliza os alunos em torno de um novo tipo de linguagem que envolve o ente matemático em questão (dialética de formulação). A legitimação do procedimento criado no SuperLogo leva os alunos a trabalharem no plano racional, buscando explicar o comando criado para a construção das figuras (dialética de validação). Então, ao final do encontro, foi destinado um momento para a socialização do conhecimento produzido pelos estudantes, fixando o estatuto formal do conhecimento matemático envolvido (institucionalização). Os destaques em torno destas dialéticas, no entanto, são possíveis a partir desta perspectiva de análise, o que não quer dizer que ocorreram linearmente ou de forma isolada; pelo contrário, o movimento característico de resolução das atividades obedeceu a uma lógica de interações intensivas, nas quais as dialéticas ocorriam em diversos momentos e até simultaneamente em alguns casos.

\section{Considerações finais}

A análise da resolução das atividades propostas à luz das teorias descritas indicou várias evidências acerca da compreensão do tema matemático em jogo. As diversas representações dos objetos envolvidos, principalmente em suas versões algébrica e geométrica, denotam os caminhos percorridos pelos estudantes e as estratégias que adotaram, 
mesmo aquelas assumidas em caráter provisório. Deve-se ressaltar, mais uma vez, que o conhecimento acerca do teorema de Pitágoras estava em desenvolvimento e apenas recentemente, ao longo das sessões anteriores, havia sido alcançado pelos estudantes, também de forma autônoma.

A organização das atividades é outro ponto fulcral. A constituição de problemas adequados, assim vistos como aqueles em relação aos quais os aprendizes não possuem todas as ferramentas cognitivas necessárias à resolução em um primeiro momento, incentivou trajetórias de experimentação intensiva com uso do SuperLogo e de tecnologias tradicionais, como se viu com o lápis e papel, em apoio às conjecturas e constructos provisórios, submetidos à validação no diálogo com os pares. Estes problemas se mostraram, então, convenientes para que os sujeitos conjecturassem, refletissem, opinassem e refizessem um sem número de vezes suas proposições, até delas se convencerem, tendo como base o conhecimento matemático procurado - no caso, o próprio teorema de Pitágoras.

Como subsídio para a existência de uma aprendizagem significativa, Ausubel (2002) aponta a existência de conhecimentos prévios que sirvam de ancoradouro para o novo conhecimento. A construção da situação-problema considerou como premissa os conceitos de geometria plana que os estudantes já detinham em sua estrutura cognitiva. Outra condição apontada pelo pesquisador norte-americano é a motivação dos estudantes em relacionar as informações novas à estrutura cognitiva, de maneira substantiva e não arbitrária. Em todas as sessões, os sujeitos demonstraram a intenção de realizar as construções geométricas, sem que houvesse a preocupação em executar roteiros pré-concebidos, típicos das propostas instrucionistas.

No sentido apontado por Ausubel (2002), os sujeitos tiveram a oportunidade de reestruturar o conjunto de informações presentes, integrá-las à estrutura cognitiva e reorganizar o conhecimento, de forma a relacionar as medidas da altura do triângulo equilátero à medida de seus lados, por exemplo. Com efeito, ao final das atividades, os alunos foram capazes de enunciar corretamente o Teorema de Pitágoras sem que houvesse qualquer abordagem expositiva, de modo a indicar a existência de um produto interacional entre o que os conhecimentos subsunçores e o novo conhecimento emergido a partir das investigações proporcionadas pela sequência didática.

Vale ressaltar que a utilização do SuperLogo colaborou para a realização da sequência didática, tanto por viabilizar a experimentação dos conceitos matemáticos abordados, quanto por possibilitar discussões acerca de um tipo de linguagem, na qual subentende-se um 
conjunto de regras e uma lógica interna. Precisa ser ressaltada a observação, ao longo das interações ocorridas, de que, gradualmente, a tecnologia digital se integrava aos meios de produzir o conhecimento que já eram dominados pelos sujeitos antes da pesquisa, provocando reorganizações no pensamento dos estudantes e auxiliando no estabelecimento de vínculos entre o conhecimento matemático e a lógica da interface. Assim, outra anotação aqui ocorre por conta da percepção de que o conhecimento foi se constituindo a partir de um trabalho de trocas intensas, tendo por unidade de autoria os coletivos de pessoas-com-SuperLogo e pessoas-com-lápis-e-papel, em regime de convergência, possibilidade esta apontada pelos estudos de Borba e Villarreal (2005) e considerada, igualmente, no constructo do ciclo, proposto por Oliveira (2013).

Embora o registro dos resultados obtidos tenha sido satisfatório no âmbito da pesquisa, acredita-se que as questões levantadas mereçam aprofundamentos e discussões que permitam seu aperfeiçoamento e a análise de outros elementos que, eventualmente, tenham sido desconsiderados. Tais avanços podem surgir a partir de novas pesquisas, as quais poderiam, eventualmente, empregar estes resultados de alguma forma.

\section{Referências}

ALMOULOUD, S. A. Fundamentos da didática da matemática. 2. ed. Curitiba: Editora UFPR, 2007.

AUSUBEL, D. P. Adquisición y retención del conocimiento: una perspectiva cognitiva. Trad. G. S. Barberán. 1. ed. Barcelona: Paidós, 2002.

BOGDAN, R. C; BIKLEN, S. K. Investigação qualitativa em educação. 1. ed. Porto: Porto Editora, 1994.

BORBA, M. C; VILLARREAL, M. Humans-with-media and the reorganization of mathematical thinking: information and communication technologies, modelling, visualization and experimentation. 1. ed. New York: Springer, 2005.

BOURDIEU, P.; PASSERON, J. C. A reprodução: elementos para uma teoria do sistema de ensino. 5. ed. Rio de Janeiro: Vozes, 2008.

BROSSEAU, G. Introdução ao estudo das situações didáticas: conteúdos e métodos de ensino. Trad. Camila Bógea. 1. ed. São Paulo: Ática, 2008.

BROSSEAU, G. Theory of didactical situations in mathematics: didactique dês mathématiques, 1970-1990. 1. ed. Dordrecht: Kluwer Academic Publishers, 2002.

FIORENTINI, D.; LORENZATO, S. Investigação em educação matemática: percursos teóricos e metodológicos. 1. ed. Campinas: Autores Associados, 2006. 
FREUDENTHAL, H. Mathematics as an educational task. 2. ed. Dordrecht: D. Reidel Publishing, 1973.

LÉVY, P. As tecnologias da inteligência: o futuro do pensamento na era da informática. 2. ed. Rio de Janeiro: Editora 34, 1993.

MAOR, E. The Pythagoeran Theorem: a 4000-year history. 1. ed. New Jersey: Princenton University Press, 2007.

OLIVEIRA, G. P. Tecnologias digitais na formação docente: estratégias didáticas com uso do superlogo e do geogebra. In: CONGRESO IBEROAMERICANO DE EDUCACIÓN

MATEMÁTICA, 7., 2013, Montevideo. Anais... Montevideo: Sociedad de Educación Matemática Uruguaya, 2013, 1 v. 359 p.

OLIVEIRA, G. P. Transposição didática: aportes teóricos e novas propostas. In: WITTER, G. P.; FUJIWARA, R. Ensino de Ciências e Matemática: análise de problemas. São Paulo: Ateliê Editorial, 2009. p. 209-236

TIKHOMIROV, O. K. The psychological consequences of computerization. In: WERTSCH, J. V. (Org.). The concept of activity in soviet psychology. New York: M. E. Sharpe. Inc, 1981. p. 256278.

Submetido em 24 de Maio de 2017. Aprovado em 04 de Janeiro de 2018. 